\title{
MICROSTRUCTURAL INVESTIGATION AND SELECTED PROPERTIES OF NI-CR-RE-AL2O3 COATINGS DEPOSITED BY MEANS OF HVOF THERMAL SPRAYING
}

\author{
${ }^{1}$ Beata SKOWROŃSKA, ${ }^{1}$ Dariusz GOLAŃSKI, ${ }^{2}$ Marcin CHMIELEWSKI, ${ }^{1}$ Tomasz CHMIELEWSKI \\ ${ }^{1}$ Warsaw University of Technology, Faculty of Production Engineering, Warsaw, Poland, EU, \\ beata.skowronska@pw.edu.pl \\ ${ }^{2}$ Łukasiewicz Research Network, Centre of Electronic Materials Technology, Warsaw, Poland, EU, \\ marcin.chmielewski@imif.lukasiewicz.gov.pl
}

\section{https://doi.org/10.37904/metal.2021.4193}

\begin{abstract}
The paper presents selected results of microstructural investigation of $\mathrm{Ni}-\mathrm{Cr}-\mathrm{Re}$ with the addition of aluminium oxide coatings, deposited by means of HVOF thermal spray. The substrate made of $16 \mathrm{Mo} 3$ chromium molybdenum boiler steel was coated with a powder material of Oerlikon Amdry $453580 \% \mathrm{Ni}, 20 \% \mathrm{Cr}$, $20 \div 45 \mu \mathrm{m}$, to which $1 \%$ of metallic rhenium and $10 \%$ of Al2O3 was dopped using the high energy milling method in a ball mill. The Rhenium and alumina are an addition in shape of inclusions that improves the heat resistance of alloys, creep, and high temperature oxidation resistance. Alloys with the addition of rhenium and alumina are widely used in the power industry. Metallographic microscopic examinations, microhardness tests and surface profilometry were carried out.
\end{abstract}

Keywords: Thermal spraying, protective coating, heat resistance, microstructure, Re addition, rhenium, coating

\section{INTRODUCTION}

The High Velocity Oxy Fuel (HVOF) thermal spraying process consists in heating the coating material in a high energy flame in the form of powder (less often wire) and high velocity transporting plasticized and partially melted particles onto the substrate material. HVOF spraying apparatus in action is shows (Figure 1). Metallic, ceramics and even composite powders are commonly used. The most common fuel in the HVOF spraying process is kerosene burned in oxygen. Coatings with a thickness of $0.05 \div 2 \mathrm{~mm}$ and a density of up to $98 \%$ are obtained [1].

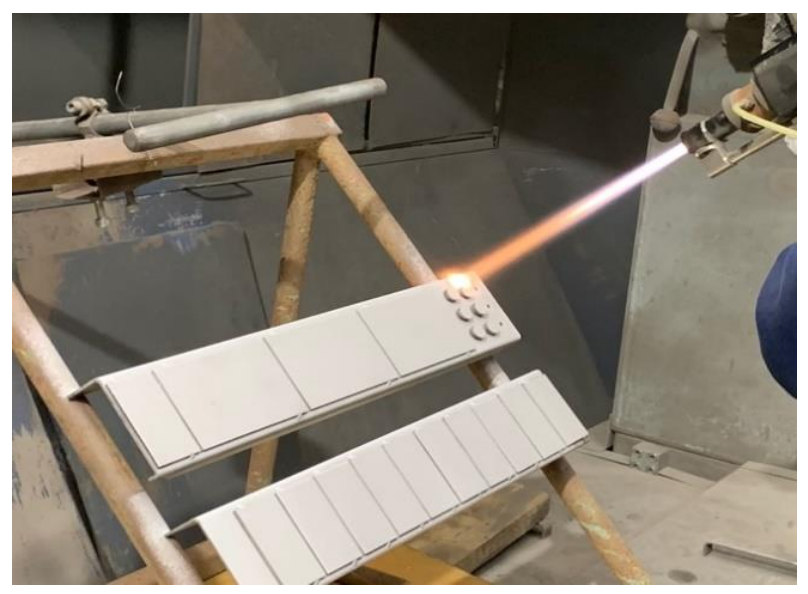

Figure $1 \mathrm{HVOF}$ thermal spraying process 
In order to obtain sufficiently good adhesion of the coating, apart from well-chosen parameters of the spraying process, it is also necessary to properly prepare the surface of the base material by means of abrasive blasting [2]. The substrate surface ready to coat process is considered as a dry, degreased surface, free from oxides and impurities, and above all, with an appropriate roughness. The surface profile should be irregular and heterogeneous [3] and have a kind of inequalities in which particles of plasticized material can be deposited [4].

Rhenium is a dark silvery refractory transition metal element with an atomic number of 75 and an atomic mass of 186.2. It has a very high melting point $\left(3180^{\circ} \mathrm{C}\right)$. Young's modulus $(470 \mathrm{GPa})$. It is characterized by the fourth highest density $(21.02 \mathrm{~g} \mathrm{/} \mathrm{cm3})$. At $2700 \div 2800{ }^{\circ} \mathrm{C}$ and under high stress conditions, the tensile and creep strength of rhenium at high temperature is much higher than that of tungsten (at temperatures up to $1250{ }^{\circ} \mathrm{C}$ it exceeds twice). The addition of rhenium to the $\mathrm{Ni}-\mathrm{Cr}$ powder is to increase the thermal resistance of the obtained coating and to improve the resistance to high-temperature oxidation [5]. The use of the Al2O3 additive was to increase the oxidation resistance of the coating, but also to increase the wear resistance [6] e.g. due to the potential impact of ash in the boiler.

The aim of the paper is to prepare and evaluate coatings in accordance with the developed technology of HVOF spraying of nickel-chromium powder with the addition of Rhenium and $\mathrm{Al} 2 \mathrm{O} 3$ (Ni-Cr-Re-Al2O3) on the substrate made of $16 \mathrm{Mo} 3$ boiler steel. The research checked how the addition of ceramics will affect the formation of the coating structure.

\section{METHODS, MATERIALS AND DEVICES}

The main coating material powder was Amdry $4535 \mathrm{Ni}-\mathrm{Cr}$ (80\%-20\%) from Oerlikon company, Re powder from KGHM with $150 \mu \mathrm{m}$ granulation (purity 99.7\%). The $\mathrm{Al}_{2} \mathrm{O}_{3}$ purity $99.7 \%$ and average size (LD) $3.06 \mu \mathrm{m}$. Due to the relatively large initial size of rhenium grains, it was subjected to a process of grinding by milling in a highenergy planetary mill with the following parameters: $200 \mathrm{rpm}$, BPR 5: 1, time $4 \mathrm{~h}$. In the next step the powder of $\mathrm{Al}_{2} \mathrm{O}_{3}$ has been added to the mill chamber and process of mixing has been repeated. After mixing, the powders were subjected to microscopic observation. In addition, surface distribution analysis of the elements (EDS) was performed. The morphology of the obtained powder mixtures is shown in (Figure 2). SEM images and surface analysis of the elements showed that the rhenium (yellow inclusions) powder introduced into the mixture tends to hammer to the $\mathrm{Ni}-\mathrm{Cr}$ particles. $\mathrm{Al}_{2} \mathrm{O}_{3}$ particles seem to partially free and occluded only (not connected permanently).
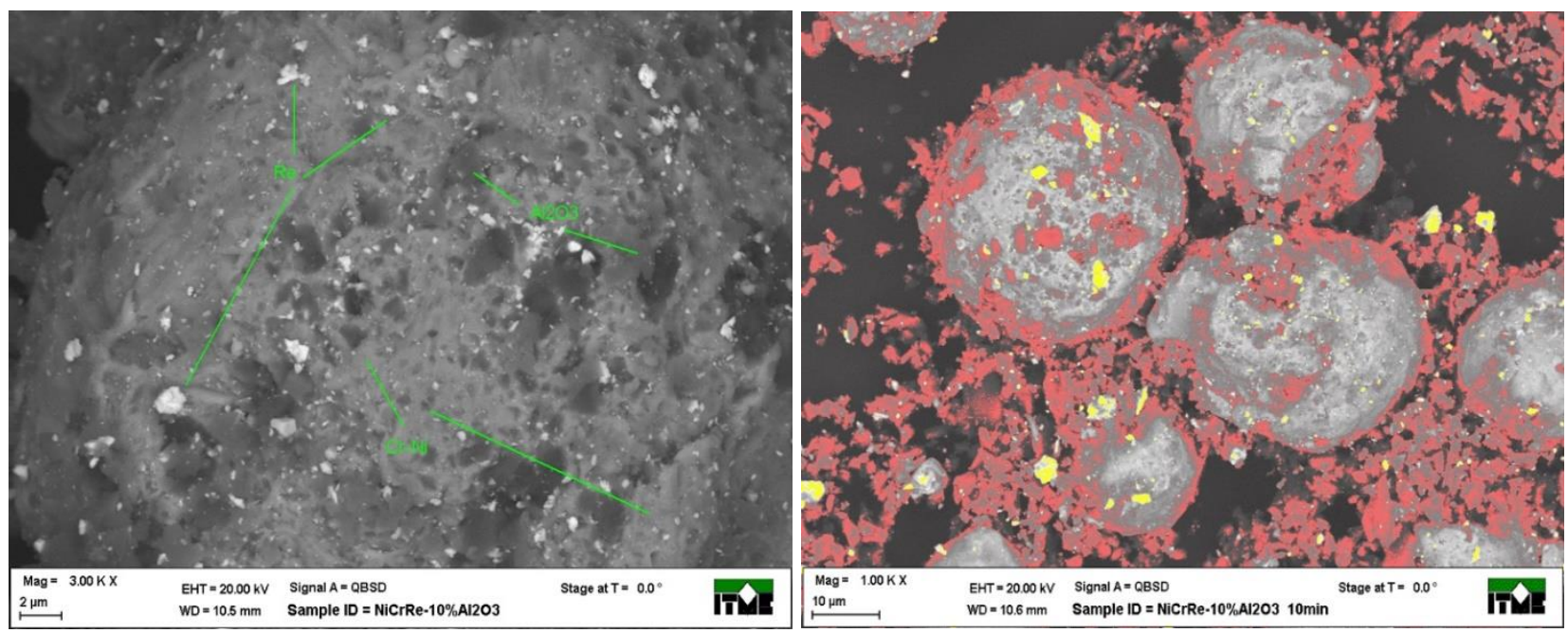

Figure 2 SEM images of: $\mathrm{Ni}-\mathrm{Cr}+\mathrm{Re}+\mathrm{Al}_{2} \mathrm{O}_{3}$ 
The coatings were made using the HVOF Spray System. Prior to spraying, the powder was dried at $300{ }^{\circ} \mathrm{C}$ for 50 hours and then sieved through a $50 \mu \mathrm{m}$ sieve. 10 steel plates are welded to the C-profile steel to avoid shifting during spraying, allowing a uniform coating and better heat dissipation. The substrate was grit blasted with F36 alumina. The roughness Ra after blasting averaged $6.3 \mu \mathrm{m}$. The channel was attached to the about $45^{\circ}$ oriented plate on the rack (Figure 1). The additive material in the form of a powder was supplied with an argon stream.

\section{RESULTS}

Before the invasive and destructive tests, optical roughness measurements were carried out on the Sensofar $S$ Neox profilometer. The surface roughness of the coating was measured. The three-dimensional map of the coating surface distribution is shown in the (Figure 3).

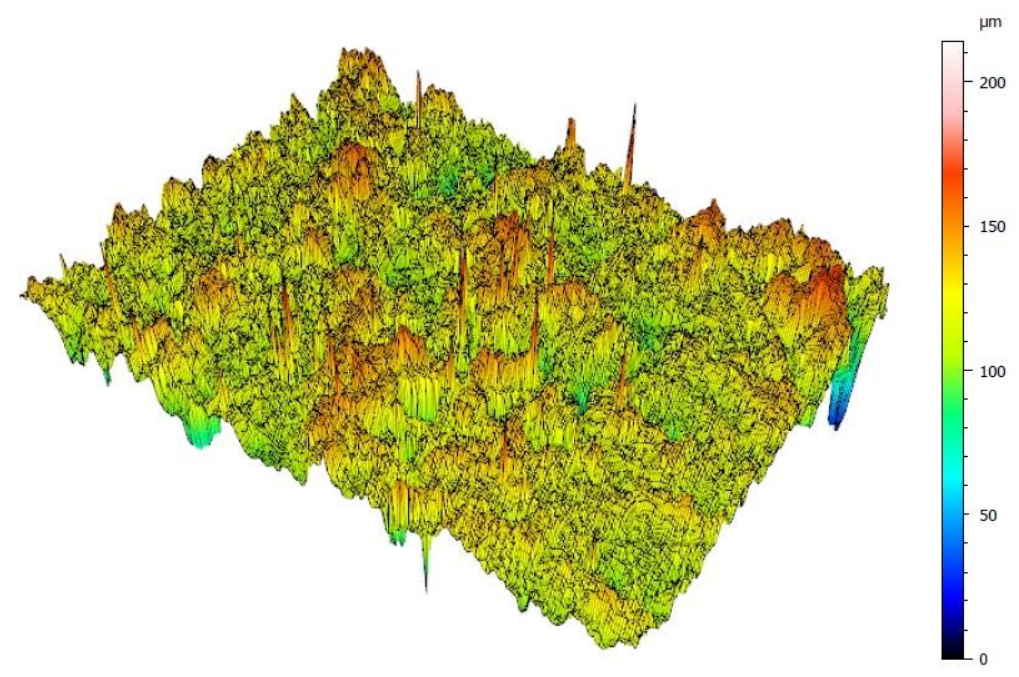

Figure 3 Three-dimensional map of coating surface deposited by the means of HVOF thermal spraying

Figure 4 shows the microstructure of the substrate-coating system. Coatings with a thickness of about 550 $\mu \mathrm{m}$ were obtained. The $16 \mathrm{Mo} 3$ steel substrate with a ferritic-pearlitic structure is characterized by an even grain distribution.

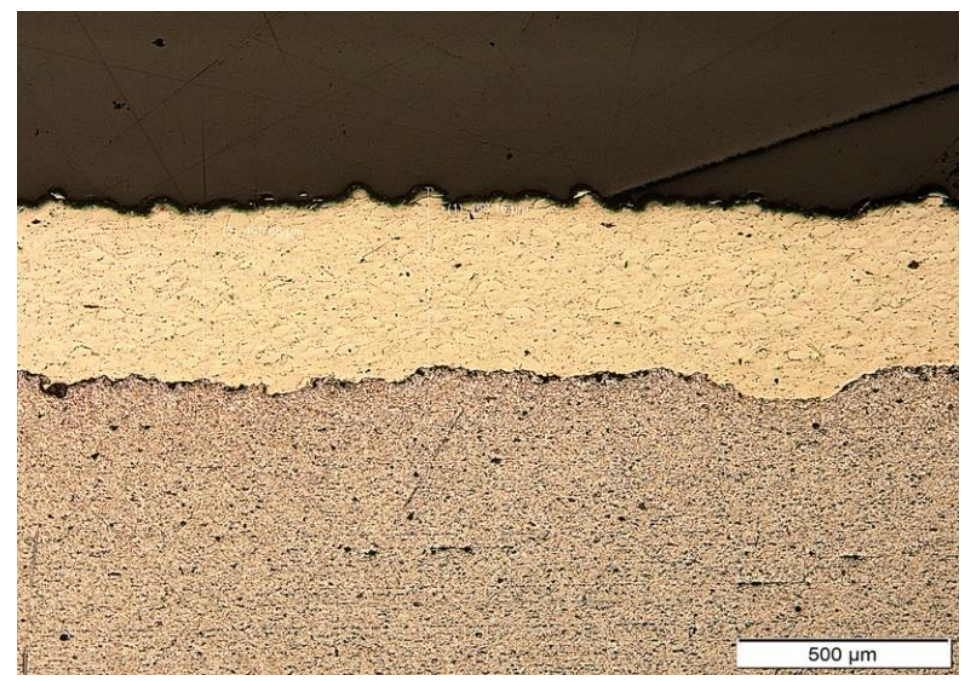

Figure 4 Microstructure of $16 \mathrm{Mo} 3$ steel substrate and $\mathrm{Ni}-\mathrm{Cr}+\mathrm{Re}+\mathrm{Al}_{2} \mathrm{O}_{3}$ coating 
Figure 5 shows the microstructure of the coating observed using an optical microscope. The dark phase represents the distribution of $\mathrm{Al}_{2} \mathrm{O}_{3}$ particles in the coating, the weight proportion of which is about $10 \%$. The structure of the coating shows deformed $\mathrm{Ni}$-Cr powder particles in which the inclusions are scattered randomly in the form of Re particles with dimensions of a few micrometres. On the bounder of grains there are $\mathrm{Al}_{2} \mathrm{O}_{3}$ particles located.

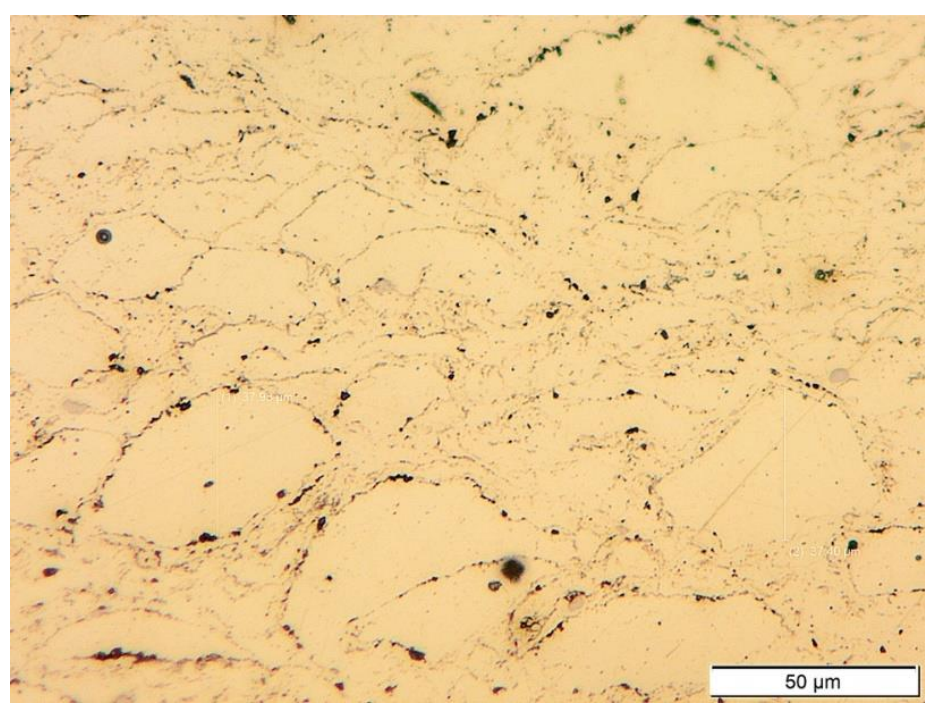

Figure 5 Microstructure of substrate and $\mathrm{Ni}-\mathrm{Cr}+\mathrm{Re}+\mathrm{Al}_{2} \mathrm{O}_{3}$ coating (OM)

The HVOF coating has a noticeable share of small and large pores. The small, closed pores are usually caused by trapped gases. Most of the larger pores are due to the formation of pits at the boundaries of the overlapping lamellae. In the HVOF spraying method, the powder has been melted in a flame with high thermal energy and deposited on a substrate in a semi-molten form in an open atmosphere, resulting in a porous structure with a high content of oxides. The cross-section of the coatings shows lamellar structures with the presence of thin oxide coatings, which is characteristic of HVOF spraying. These oxides have been observed to follow the grain boundaries. A characteristic "two-zone" microstructure is observed on the surfaces of the sprayed coatings. It is made of well-melted lamellae, and between them there are sintering zones with grains on a submicrometric scale.

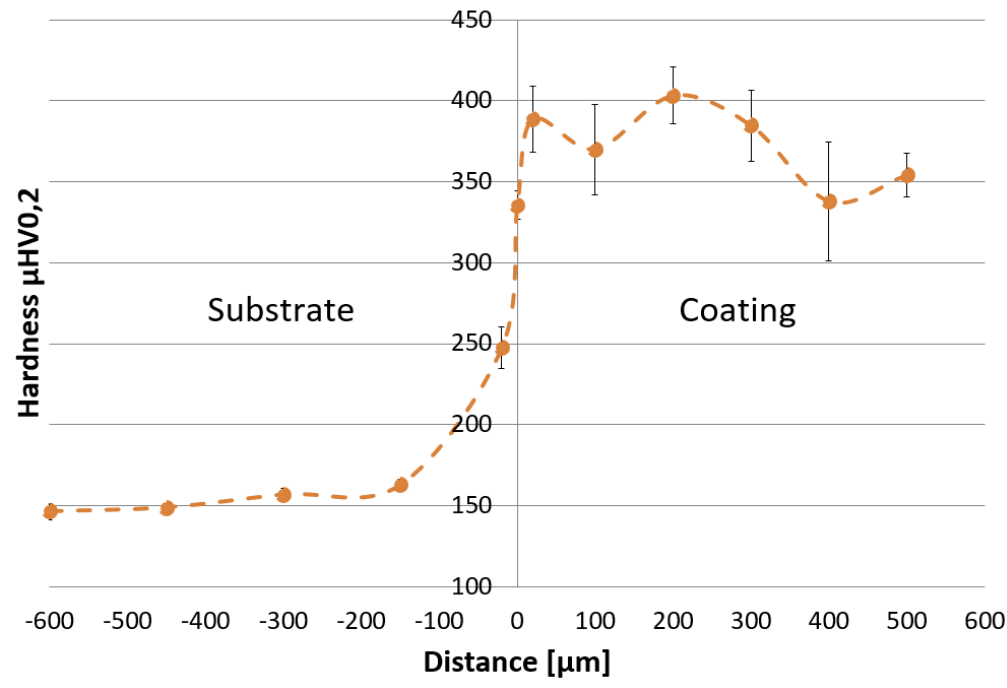

Figure 6 Hardness distribution in substrate-coating system 
The next step was to measure the hardness of the coating using the Vickers method according to EN ISO 6507-1. The measurements were carried out under a load of $1.961 \mathrm{~N}$, and the results are presented in the diagram (Figure 6). The graph shows the average hardness value from 5 measurement series with the standard deviation for the measurement point at the $95 \%$ confidence level.

The hardness of the $16 \mathrm{Mo} 3$ steel substrate is approximately $150 \mathrm{HV} 0.2$. The low standard deviation at each measuring point proves the homogeneity of the base material. The coating hardness is in the range of 340$400 \mathrm{HV}$ 0.2. High standard deviation bars indicate a heterogeneous and irregular structure of the coating.

\section{CONCLUSION}

The High Velocity Oxy Fuel thermal spraying process is characterized by high application flexibility. With the appropriate selection of parameters, we can use various coating materials and metal [7]. This method can be used for repair and regeneration purposes as well as for preventive purposes. Unfortunately, the sprayed coatings are porous. In many cases, it is a good alternative to conventional surface modification methods [8]. Oxide layers along the transition line and between successive applied layers are a common defect observed in spray coatings. [9] The coating material based on nickel and chromium is highly corrosion resistant. The addition of metallic Rhenium and $\mathrm{Al} 2 \mathrm{O} 3$ to the powder increases the heat resistance of the alloy obtained in the process. A protective coating of this chemical composition increases resistance to high-temperature oxidation.

The interface between the coating and the substrate shows no defects and discontinuities. The coating material evenly fills the unevenness of the substrate surface. Correct coatings with proper adhesion to the substrate were obtained. The obtained HVOF sprayed Ni-Cr+Re+$+\mathrm{Al}_{2} \mathrm{O}_{3}$ coating has a higher hardness than the ferriticperlitic substrate made of $16 \mathrm{Mo} 3$ steel, oscillating around the value of $400 \mathrm{HV} 0.2$. The structure of the coating reveals relatively evenly dispersed $\mathrm{Re}$ and $\mathrm{Al}_{2} \mathrm{O}_{3}$ particles, which can be easily identified in the SEM image due to the high density of rhenium. In the microscopic image, we observe them in the form of bright inclusions with dimensions of a few micrometres. The sprayed coating has a regular microstructure with a lamellar structure characteristic for this method of preparation. Characteristic thin oxide films for HVOF sprayed coatings are visible between the powder particles from which the coating was formed. There are evenly inclusions of rhenium particles in the coating inside of grains mainly. The $\mathrm{Al}_{2} \mathrm{O}_{3}$ inclusions are on the grain boundaries.

\section{ACKNOWLEDGEMENTS}

This research was funded by NCBR, ,Innovative Ni-Cr-Re coatings with enhanced corrosion and erosion resistance for high temperature applications in power generation industry" grant number NICRRE project4249 M-ERA.NET Call 2016, agreement number M-ERA.NET2/2016/01/2017

\section{REFERENCES}

[1] CZUPRYNSKI, A., GÓRKA, J., ADAMIAK, M., TOMICZEK, B. Testing of flame sprayed AI2O3 matrix coatings containing TiO2. Archives of Metallurgy and Materials. [online]. 2016, vol. 61, no. 3, pp. 1017-1024. Available from: https://doi.org/10.1515/amm-2016-0224.

[2] CHMIELEWSKI, T., HUDYCZ, M., KRAJEWSKI, A., SALACINSKI, T., SKOWRONSKA, B., ŚWIERCZ, R. Structure investigation of titanium metallization coating deposited onto AIN ceramics substrate by means of friction surfacing process. Coatings. [online]. 2019, vol. 9, no. 12, p. 845. Available from: https://doi.org/10.3390/coatings9120845.

[3] KLIMPEL, A., CZUPRYNSKI, A., GÓRKA, J., KIK, T., MELCER, M. A study of modern materials for arc spraying. Welding International. [online]. 2014, vol. 28, no. 2, pp. 100-106. Available from: https://doi.org/10.1080/09507116.2012.708479. 
[4] CHMIELEWSKI, T., SIWEK, P., CHMIELEWSKI, M., PIATKOWSKA, A., GRABIAS, A., GOLAŃSKI, D. Structure and selected properties of arc sprayed coatings containing in-situ fabricated Fe-Al intermetallic phases. Metals. [online]. 2018, vol. 8, no. 12, p. 1059. Available from: https://doi.org/10.3390/met8121059.

[5] KOŁODZIEJCZAK, P., GOLAŃSKI, D., CHMIELEWSKI, T., CHMIELEWSKI, M. Microstructure of Rhenium Doped Ni-Cr Deposits Produced by Laser Cladding. Materials. [online]. 2021, vol. 14, no. 11, p. 2745. Available from: https://doi.org/10.3390/ma14112745.

[6] MICHALAK, M., LATKA, L., SOKOLOWSKI, P., TOMA, F.-L., MYALSKA, H., DENOIRJEAN, A., AGEORGES, H., Microstructural, mechanical and tribological properties of finely grained Al2O3 coatings obtained by SPS and SHVOF methods. Surface \& coatings technology. [online]. 2020, vol.404, p. 126463, Available from: https://doi.org/10.1016/j.surfcoat.2020.126463.

[7] LI C, J., OHMORI, A. Relationships between the microstructure and properties of thermally sprayed deposits. Journal of Thermal Spray Technology. [online]. 2003, vol. 11, no. 3, pp. 365-374. Available from: https://doi.org/10.1361/105996302770348754.

[8] PAWŁOWSKI, A., CZEPPE, T., MAJOR, Ł., SENDEROWSKI, C. Structure morphology of Fe-Al coatings detonation sprayed onto carbon steel substrate. Archives of Metallurgy and Materials. 2009, vol. 54, no. 3, pp. 783-788.

[9] LATKA, L., SZALA, M., MICHALAK, M., PAŁKA, T. Impact of atmospheric plasma spray parameters on cavitation erosion resistance of Al2O3-13\% TiO2 coatings. Acta Physica Polonica A. [online]. 2019, vol. 13, no. 2, pp. 342347. Available from: https://doi.org/10.12693/APhysPolA.136.342. 